\title{
Recovery of Cerium from Glass Polishing Waste: A Critical Review
}

\author{
Chenna Rao Borra ${ }^{1, * \mathbb{D}}$, Thijs J. H. Vlugt ${ }^{2}$, Yongxiang Yang ${ }^{1}$ and S. Erik Offerman ${ }^{1}$ \\ 1 Department of Materials Science and Engineering, Delft University of Technology, Mekelweg 2, \\ 2628CD Delft, The Netherlands; y.yang@tudelft.nl (Y.Y.); s.e.offerman@tudelft.nl (S.E.O.) \\ 2 Process \& Energy Department, Delft University of Technology, Leeghwaterstraat 39, \\ 2628CB Delft, The Netherlands; t.j.h.vlugt@tudelft.nl \\ * Correspondence: c.r.borra@tudelft.nl; Tel.: +31-620230363
}

Received: 30 August 2018; Accepted: 30 September 2018; Published: 6 October 2018

check for updates

\begin{abstract}
Ceria is the main component in glass polishing powders due to its special physico-chemical properties. Glass polishing powder loses its polishing ability gradually during usage due to the accumulation of other compounds on the polishing powder or due to changes in the particle size distribution. The recovery of cerium from the glass polishing waste results in the efficient utilization of natural resources. This paper reviews processes for the recovery of rare earths from polishing waste. Glass polishing powder waste can be reused via physical, physico-chemical or chemical processes by removing silica and/or alumina. The removal of silica and/or alumina only improves the life span up to some extent. Therefore, removal of other elements by chemical processes is required to recover a cerium or cerium-rich product. However, cerium leaching from the polishing waste is challenging due to the difficulties associated with the dissolution of ceria. Therefore, high acid concentrations, high temperatures or costly reducing agents are required for cerium dissolution. After leaching, cerium can be extracted from the leach solution by solvent extraction or selective precipitation. The product can be used either in glass polishing again or other high value added applications.
\end{abstract}

Keywords: cerium; flotation; glass polishing waste; gravity separation; leaching; precipitation; rare-earths; recycling; reuse; solvent extraction

\section{Introduction}

\subsection{Rare-Earth Elements}

Rare-earth elements (REEs) are a group of 17 chemically similar elements that include the lanthanides, yttrium and scandium. Rare-earth elements are divided into light rare-earth elements (LREEs), ranging from lanthanum to europium, and the heavy rare-earth elements (HREEs), ranging from gadolinium to lutetium, and yttrium [1]. Total worldwide production of REEs is about 130,000 $\mathrm{t}$ out of which $80 \%$ of REEs are produced in China [2]. Primary production of REEs generates large amount of pollution such as radiation, acid effluents generation, fluoride contamination, etc. [3]. Some of the REEs ( $\mathrm{Pr}, \mathrm{Nd}, \mathrm{Eu}, \mathrm{Tb}, \mathrm{Dy}$ and $\mathrm{Y}$ ) are important for the low carbon economy, as they are used in wind turbines, electric vehicles, and energy efficient lighting. These elements comes under the list of critical elements due to the supply risk [4]. However, cerium and lanthanum are not on the critical elements list as they are over produced during critical REEs production [5].

Cerium

Cerium is the most abundant element in all REEs [1]. Principal ores of cerium are the minerals bastnasite $\left((\mathrm{REE}) \mathrm{CO}_{3} \mathrm{~F}\right)$, monazite $\left((\mathrm{Ce}, \mathrm{La}, \mathrm{Nd}, \mathrm{Th}) \mathrm{PO}_{4}\right)$, loparite $\left((\mathrm{Ce}, \mathrm{Na}, \mathrm{Ca})(\mathrm{Ti}, \mathrm{Nb}) \mathrm{O}_{3}\right)$ and lateritic 
ion-adsorption clays [6]. The total global cerium containing mineral reserves are estimated to be 30 million tons [7] and the current production of ceria $\left(\mathrm{CeO}_{2}\right)$ is about $54,400 \mathrm{t}$ ( $32 \%$ of RE oxides). Current price of $\mathrm{CeO}_{2}$ is about $3 \mathrm{USD} / \mathrm{kg}$ [6]. Important applications of cerium includes catalysts, glass additives, polishing, ceramics, phosphors, LEDs etc. [1]. About 40,000 t of RE oxides are consumed by glass industry, out of which about 16,000 tons are being used for polishing applications [8].

\subsection{Glass Polishing Powder and Its Applications}

The hardness of the polishing powder plays very important role in glass polishing [9]. The hardness of polishing powder should be similar to the glass to avoid deep penetration of the polishing grains and formation of large grooves. The average hardness for some glasses and polishing powders are listed in Table 1. In addition to hardness, the polishing rate is also an important factor for the selection of the polishing powder. The polishing rate of glass depends on the isoelectric $\mathrm{pH}$ ( $\mathrm{pH}$ level where the zeta potential is zero) of the polishing powder. Silvernail found a relation between isoelectric $\mathrm{pH}$ of different oxides with respect to their polishing rates [10], which is shown in the Figure 1. Being an amphoteric oxide, ceria can exchange both cations $\left(\mathrm{Na}^{+}, \mathrm{Ca}^{2+}\right.$, etc.) and anions (silicate, phosphate, etc.). Based on the two criteria (isoelectric $\mathrm{pH}$ and hardness), ceria is the best polishing agent compared to other oxides such as zirconia and alumina.

Table 1. Hardness values of different polishing powders and different type of glasses [9].

\begin{tabular}{cccc}
\hline Polishing Powder & $\begin{array}{c}\text { Hardness } \\
\text { (Mohs Scale) }\end{array}$ & Type of Glass & $\begin{array}{c}\text { Hardness } \\
\text { (Mohs Scale) }\end{array}$ \\
\hline Diamond & 10 & Silica & 7 \\
Alumina & 9 & Soda lime & 5.3 \\
Zirconia & 8 & Borosilicate & 5.8 \\
Ceria & $7-8$ & Lead & 4.8 \\
\hline
\end{tabular}

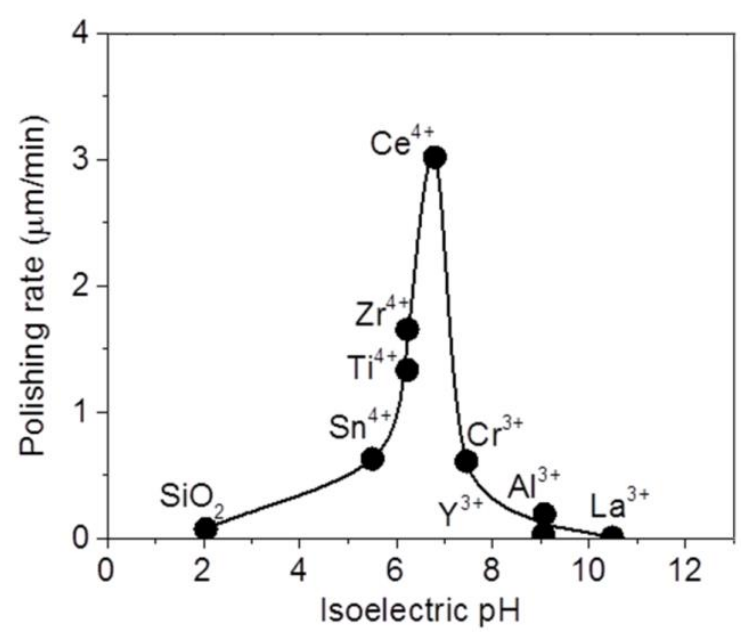

Figure 1. Relation between isoelectric $\mathrm{pH}$ (where the concentrations of positively and negatively charged species at the surface are equal) of different polishing compounds with respect to glass polishing rate data. Reproduced from Cook [10], with permission from Elsevier, 2018.

The composition of different glass polishing powders available from the literature is provided in Table 2. The name glass polishing powder is a misnomer as this polishing powder is also used in polishing the silicon wafers, gems and ceramics. The use of cerium compounds as a polishing agent started in the 1930's [8,11]. Prior to 1990's, the growth was mainly due to the demand from the production of CRT screens. Since the 1990's, the demand is rapidly increased due to the rapid growth of electronic products, which require high quality polishing. Seventy five percent $(75 \%)$ of glass polishing powder is consumed in traditional glass applications (including display panels, flat glass and optical 
glass) and around $25 \%$ in electronic components. The specific application of glass polishing powders include glass, precision glass lenses, glass display panels, liquid crystal displays, glass magnetic memory disks, silicon wafers etc. [9]. A detailed list of applications can be found elsewhere [9].

Table 2. Chemical composition of different glass polishing powders.

\begin{tabular}{cccccc}
\hline Oxide & $\mathbf{L a}_{\mathbf{2}} \mathbf{O}_{\mathbf{3}}$ & $\mathbf{C e O}_{\mathbf{2}}$ & $\mathbf{P r}_{\mathbf{6}} \mathbf{O}_{\mathbf{1 1}}$ & $\mathbf{N d}_{\mathbf{2}} \mathbf{O}_{\mathbf{3}}$ & Reference \\
\hline & 31.5 & 65 & 3.5 & - & {$[5]$} \\
& 34.2 & 43.8 & 3.4 & 10.9 & {$[12]$} \\
$\mathrm{wt} \%$ & - & 62.1 & - & - & {$[13]$} \\
& $0-35$ & $50-99$ & $0-5$ & $0-15$ & {$[14]$} \\
& - & $30-99.9$ & - & - & {$[9]$} \\
\hline
\end{tabular}

\subsection{Production of Glass Polishing Powder}

Ceria-based polishing powders are usually prepared by thermal decomposition of cerium oxalates, hydroxides, acetates, or carbonates [15]. A fluorination step (with $\mathrm{HF}$ or $\mathrm{NH}_{4} \mathrm{~F}$ ) is typically performed to control the particle size range of the polishing powder [9], or to fix the basic $\mathrm{La}_{2} \mathrm{O}_{3}$ [16]. Next, sintering (annealing or calcination) is carried out at about $1000{ }^{\circ} \mathrm{C}$ to promote the final crystallization and required hardness. Sintering can increase the particle size, therefore, one or several milling steps (dry or wet) are applied to get suitable mean particle size $(<5 \mu \mathrm{m})$, and a relatively sharp particle size distribution $[9,11]$. The presence of other rare earths hardly influences the polishing efficiency of the powder [15]. However, the polishing efficiency is mainly affected by calcination time and temperature, particle size, $\mathrm{CeO}_{2}$ reactivity, additives (l-proline, l-glutamic acid etc.) and particle impurities [11].

The presence of strongly basic lanthanum oxide is likely to cause clogging of a polishing pad during polishing [16]. Therefore, the basicity is decreased by the addition of fluorine to form LaOF. The fluorine content in the polishing powder is preferred within a range from about 3 to 9 mass $\%$. If the fluorine content is low, it is not possible to sufficiently change lanthanum oxide to lanthanum oxyfluoride (LaOF) [16]. If the fluorine content is too high, the excess rare earth fluoride is likely to undergo sintering during firing, which is undesirable [16].

\subsection{Polishing Process}

A schematic representation of the polishing process with a polishing slurry is shown in Figure 2. In this process, a wafer is polished on a polishing pad using a ceria based slurry. The abrasive particles in the slurry (5-10\% of solids) [17] polishes the wafer surface with chemical-mechanical action (tribo-chemical polishing or chemical mechanical polishing (CMP) or planarization). During polishing the grinding process is enhanced by chemical interactions between polishing grains $\left(\mathrm{Ce}^{4+}\right.$ and $\left.\mathrm{Ce}^{3+}\right)$ and the glass substrate (Si-O-H) [18]. These interactions lead to bridge formation $(\mathrm{Si}-\mathrm{O}-\mathrm{Ce})$ between the glass and the abrasive particles, allowing the detachment of the glass material [19]. Water plays an important role in polishing by providing the hydroxyl ions [10].

\subsection{Glass Polishing Powder Waste}

The waste slurry generated after glass polishing contains cerium and other REEs (lanthanum, neodymium, and praseodymium), iron, aluminium, zinc, sodium, silicon, etc. [12,13,20-30]. The concentration of the elements other than REEs depends on the chemical composition of the glass, additives ( $\mathrm{pH}$ modifiers, dispersing agents, etc.) and flocculants $[9,24,26]$. The abrasive properties of the polishing powder gradually diminishes due to the enrichment of the slurry with other elements and affects the quality of the product adversely. The waste slurry generated after polishing is sent for settling the solids by flocculation, followed by filter press separation. The solid cake formed after the filter press ends up in landfills [26]. This leads to loss of valuable REEs. Furthermore, disposal of glass polishing waste incur costs. 


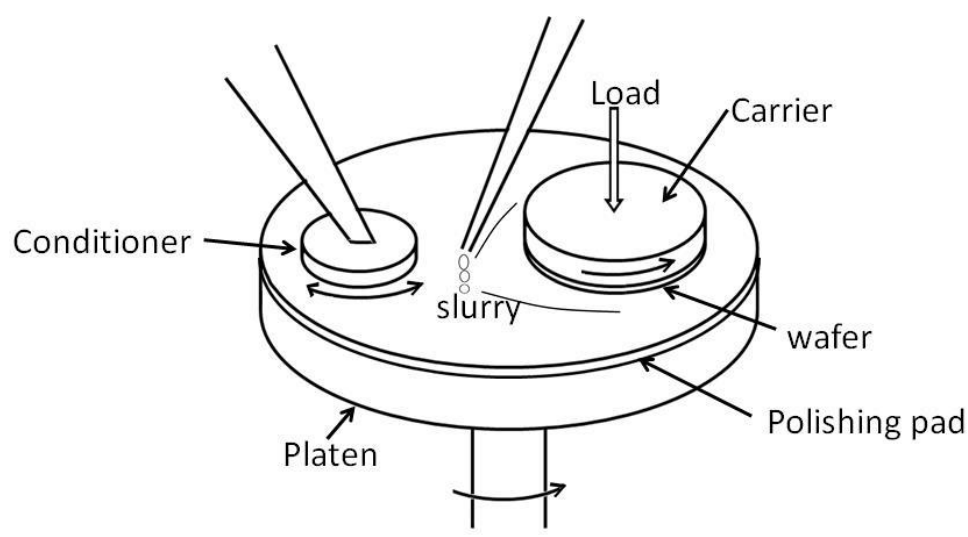

Figure 2. Schematic representation of a wafer polishing process using glass polishing powder slurry as a polishing medium.

Recycling of the polishing waste not only aids to the enhanced utilization of natural resources, but also makes recycling of valuable REEs possible. Recovery and recycling of metals from waste generally consumes less energy and results in less environmental impact when compared with primary production from an ore [31]. Furthermore, it also saves the disposal cost. The recovered cerium can be converted to cerium metal and can be used in high value aluminum and magnesium alloys and steels [32-34]. This generates highly added value from the waste and closes metal loops.

Due to the high prices and limited supply of cerium oxide since 2010, highly efficient polishing technologies that consume less amount of cerium oxide are being developed [17]. These new processes have shorter polishing times, smaller amounts of slurry and slurry re-use where possible. This decreased the polishing powder consumption by 30-50\% [35]. Different types of medium hard alumina can also be replaced with ceria for some low-end purposes [8].

Recycling of polishing waste is limited in Europe and USA, however in Japan and China this is significant [36]. Nevertheless, most of the recycling operations are currently stopped due to large price fluctuations of REEs [36]. Therefore, the new processes developed for recycling should be easily managed with small waste streams and with maximum recovery [26]. However, it is difficult to recover REEs from glass polishing waste as it is not easy to treat the waste chemically or physically [37]. The particle size distribution plays an important role in polishing [5]. Hence, the morphology of the regenerated powder from glass polishing waste should be according to the specifications, if it is reused in polishing process.

\section{Characterization of Glass Polishing Waste}

The chemical composition of different glass polishing waste samples are shown in Table 3. The waste mainly contains cerium together with other rare earths and impurities. Some of the waste contains fluorine and phosphorus which is due to the presence of fluoride and phosphate compounds of rare earths, which are very stable compounds and are not soluble in acid solutions at ambient conditions [25]. As mentioned earlier, iron and aluminum are present in the polishing waste due to the hydrolysis of the flocculants like aluminum chlorides and iron chlorides that are used in the settling of solids from slurry [12]. The presence of other rare earths in the polishing powder may be due to the costs associated with the complete separation of cerium from other rare earths. Neodymium and praseodymium content in the polishing waste is lower in the recent studies when compared to older studies $[12,13,20-30]$. This may be due to the new process development or process improvement in recent years for separating the adjacent rare earths. This is also due to the high value of neodymium and praseodymium compared to cerium. The presence of fluorine is due to the fluorine treatment (with ammonium fluoride or HF) of the powder during processing in order to increase the $\mathrm{CeO}_{2}$ concentration in the solid solution [38], or to control the particle size range [9], or to neutralize the basic lanthanum oxide [16]. 
Polishing waste is a very fine material with d50 around $2 \mu \mathrm{m}$ [29] and 100\% of the particles are less than $9 \mu \mathrm{m}$. A typical SEM image of a polishing waste sample is shown in Figure 3. Kato et al. found that the cerium is in the form of $\mathrm{CeO}_{2}$ and $\mathrm{La}_{2} \mathrm{O}_{3} \cdot \mathrm{CeF}_{3}$ [12]. However, the peaks are shifted due the substitution of cerium with other rare earths. Poscher et al. [24] found that $21 \%$ of cerium is in the form of fluorobritholite and monazite. In a recent study Borra et al. [39] found $\mathrm{CeO}_{2}, \mathrm{LaO}_{0.65} \mathrm{~F}_{1.7}$ and $\mathrm{LaPO}_{4}$ phases in a polishing waste sample.

Table 3. Chemical composition of different glass polishing waste samples available in the literature.

\begin{tabular}{|c|c|c|c|c|c|c|c|c|c|c|c|c|c|c|c|}
\hline & \multicolumn{14}{|c|}{ Compound, wt $\%$} & \multirow{2}{*}{ Reference } \\
\hline & $\mathrm{CeO}_{2}$ & $\mathrm{La}_{2} \mathrm{O}_{3}$ & $\operatorname{Pr}_{6} \mathrm{O}_{11}$ & $\mathrm{Nd}_{2} \mathrm{O}$ & F (elem.) & $\mathrm{SiO}_{2}$ & $\mathrm{Al}_{2} \mathrm{O}_{3}$ & $\mathrm{Fe}_{2} \mathrm{O}_{3}$ & $\mathrm{Na}_{2} \mathrm{O}$ & $\mathrm{P}_{2} \mathrm{O}_{5}$ & $\mathrm{ZnO}$ & $\mathrm{K}_{2} \mathrm{O}$ & $\mathrm{CaO}$ & $\mathrm{PbO}$ & \\
\hline 1 & 8.8 & 1.5 & - & - & - & 57.6 & 1 & - & 13.3 & - & 2.0 & 6.9 & 2.9 & - & [23] \\
\hline 3 & $49-80$ & $1-10$ & - & $0.1-0.8$ & - & $5-10$ & - & $1.4-2.9$ & - & - & $1.2-2.5$ & - & - & $1-2$ & [27] \\
\hline 4 & 54 & - & - & - & - & 12 & - & - & - & - & - & - & - & - & [13] \\
\hline 5 & 22.3 & 17.7 & 1.41 & 0.21 & 1.8 & 0.1 & 11.5 & 0.2 & - & - & - & - & 9.3 & - & [28] \\
\hline 6 & 48.4 & 23.5 & - & - & 3.7 & 0.6 & 8.1 & 0.9 & 0.4 & 0.7 & 0.1 & - & 0.3 & - & {$[29,30]$} \\
\hline 9 & 50 & 28 & 7.4 & 4 & 9.5 & 0.6 & - & 0.3 & - & 0.1 & - & - & 0.7 & - & [21] \\
\hline 10 & 38 & 28 & 3.8 & 10 & 12 & 1.7 & - & 0.2 & - & 1.7 & - & - & 1.3 & - & [22] \\
\hline
\end{tabular}

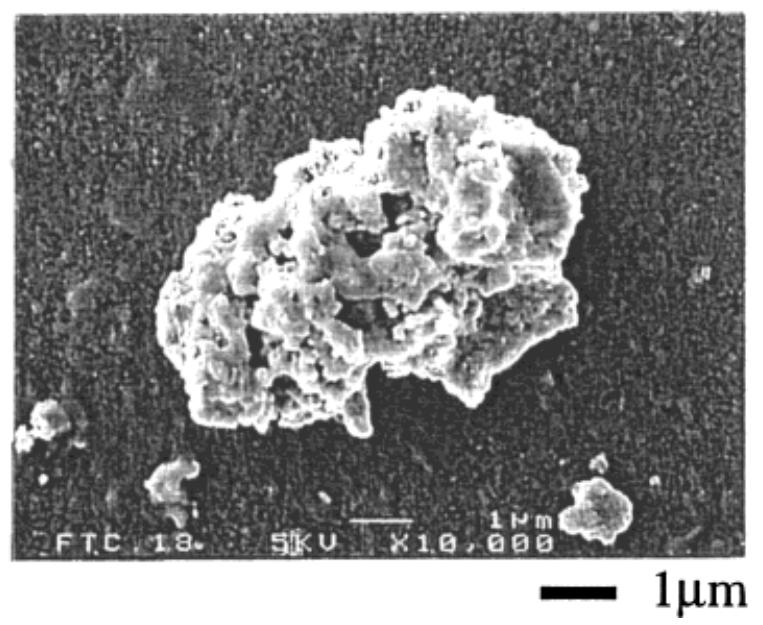

Figure 3. SEM image of a glass polishing waste sample shows fine particles. Reproduced from Kato et al. [12], with permission from American Chemical Society, 2018.

\section{Recovery of Polishing Powder (Cerium Compounds)}

As explained earlier, the polishing ability of the powder decreases after several uses. This is shown in the Figure 4. This figure also shows the effect of different kinds of polishing powders on surface roughness of the glass. It can be observed from the figure that after the removal of silica and alumina (by alkali treatment), polishing powder can be reused in polishing as the surface roughness is similar to fresh polishing powder.

Cerium can be reused or recycled from glass polishing waste by physical, physico-chemical and/or chemical methods [26,40]. Figure 5 shows an overview of different processes used for reusing and recycling of rare earths from polishing waste. Table 4 summarizes the different studies carried out on polishing waste to recover and recycle rare earths. It also gives details of reagents used and the conditions applied. 


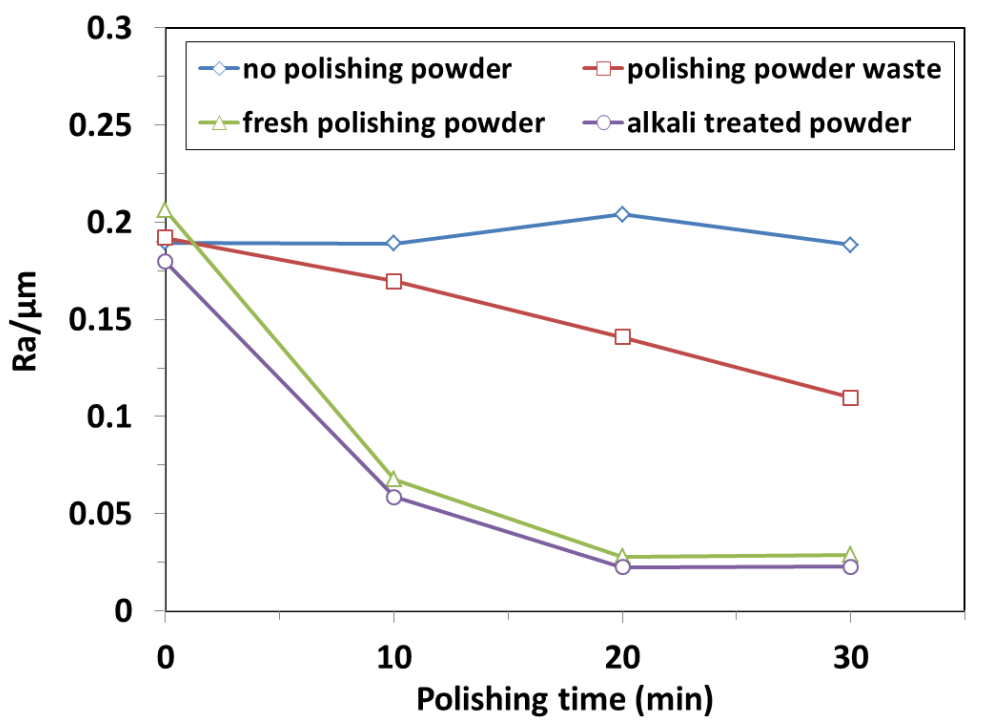

Figure 4. Effect of different polishing agents on glass polishing: the surface roughness $(\mathrm{Ra} / \mu \mathrm{m})$ as a function of polishing time. Adapted from Kato et al. [12], with permission from American Chemical Society, 2018.

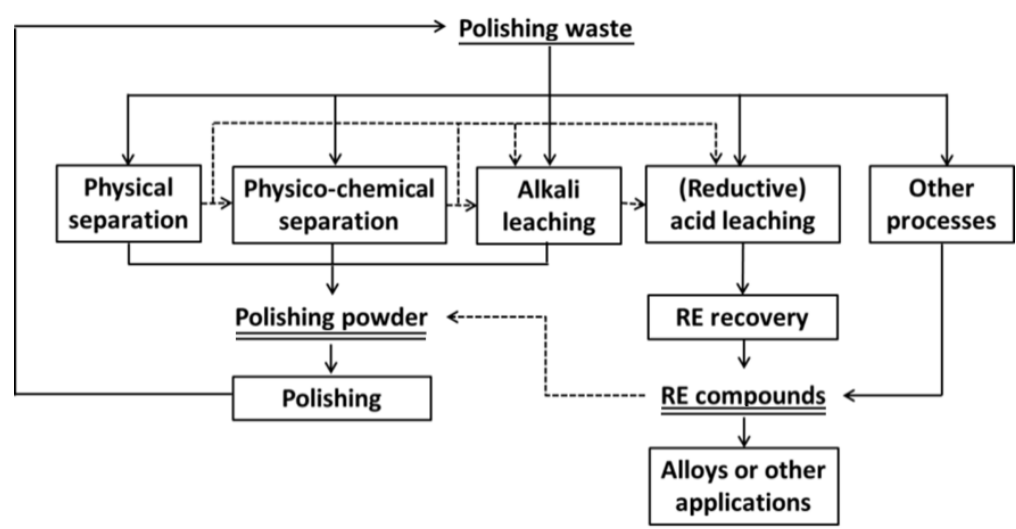

Figure 5. Different processes used for recovery of rare earths from glass polishing waste for reusing and recycling applications.

\subsection{Physical Separation}

Silica can be removed from polishing waste by physical or physicochemical separation processes like sieving, gravity separation, flotation, selective flocculation, etc. Kato et al. and Sato and Kato developed an elutriation method for removing silica [40]. In this process, the glass particles sank rapidly from polishing slurry in a first tank followed by slow separating (three days) of the supernatant solution in a second tank for settling the polishing powder particles.

Kim et al. partially removed the glass particles from waste by flotation with citric acid aqueous solution at $\mathrm{pH} \sim 1.5$ [29]. These authors found that application of ultrasound enhances the removal of silica during flotation. Liang et al. applied flotation using sodium dodecylsulfate as a collector [40]. The authors were able to recover over $99 \%$ of REEs from a synthetic mixture of REOs and glass. However, the recovery was only $40 \%$ with a purity of $44 \%$ (35\% in feed sample) when they used real slurry. Japan Oil, Gas, and Metals National Corporation (JOEGMEC) studied the removal of flocculants by homogenization followed by removing coarse particles with sieving [40]. In this study fine particles were dispersed with shearing dispersion followed by filtration using a vibrating membrane. It was proposed that the fines generated after the filtration can be used in glass polishing again.

Polishing waste can be reused after silica removal up to some extent, if the particle size distribution is similar to the original polishing powder. However, it is difficult to remove all the silica particles 
as the particle size is very small $(<5 \mu \mathrm{m})$. Due to van der Waals forces, it is difficult to separate silica from polishing waste selectively. Therefore, chemical separation processes are required for further purification (for silica and/or other elements removal).

\subsection{Chemical Separation}

\subsubsection{Alkali Leaching—for Reuse of Polishing Powder}

Alkali leaching is mainly used for the removal of silica and alumina from the polishing waste. The following reactions take place during the leaching [12].

$$
\begin{gathered}
\mathrm{SiO}_{2}+\mathrm{OH}^{-} \rightleftharpoons \mathrm{HSiO}_{3}{ }^{-} \\
\mathrm{Al}(\mathrm{OH})_{3}+\mathrm{OH}^{-} \rightleftharpoons \mathrm{Al}(\mathrm{OH})_{4}{ }^{-}
\end{gathered}
$$

Kato et al. removed most of $\mathrm{Al}_{2} \mathrm{O}_{3}$ and $\mathrm{SiO}_{2}$ from glass polishing waste by treating it with $4 \mathrm{~mol} / \mathrm{kg}$ of $\mathrm{NaOH}$ at $50-60^{\circ} \mathrm{C}$ for 1 hour [12]. These authors removed the residue (product) from the leach solution by centrifugation and also produced zeolites from the leach solution by heating it to $100{ }^{\circ} \mathrm{C}[12,41]$. The flowsheet proposed by Kato et al. is shown in the Figure 6 .

Kim et al. [29] removed the remaining glass in the waste after a flotation treatment by $\mathrm{NaOH}$ leaching with a $\mathrm{pH}$ level of 11.5. These authors proposed to reuse the slurry in glass polishing after silica removal as the particle size distribution matches with the original glass polishing slurry. However, the alumina content is still high (about $9 \%$ ) compared to silica $(0.5 \%)$. Low removal rate of alumina was observed in this study compared to the previous study by Kato et al. [12]. This may be due to the type of alumina compound or the leaching conditions.

Moon et al. [20] proposed to use sodium fluoride during $\mathrm{NaOH}$ leaching to enhance the leaching by forming Na-F-Si-O structure. These authors also claim that the addition of $\mathrm{NaF}$ and $\mathrm{Na}_{2} \mathrm{CO}_{3}$ during leaching helps in solid liquid separation as the particles of Na-F-Si-O are easy to separate from the ceria particles. Matsui et al. added $0.5 \%$ of aluminum sulfate to promote solid-liquid separation (flocculation) after leaching [13]. These authors also proposed to treat the leach residue with nitric acid ( $\mathrm{pH}$ 5.8) for complete removal of alkali compounds.

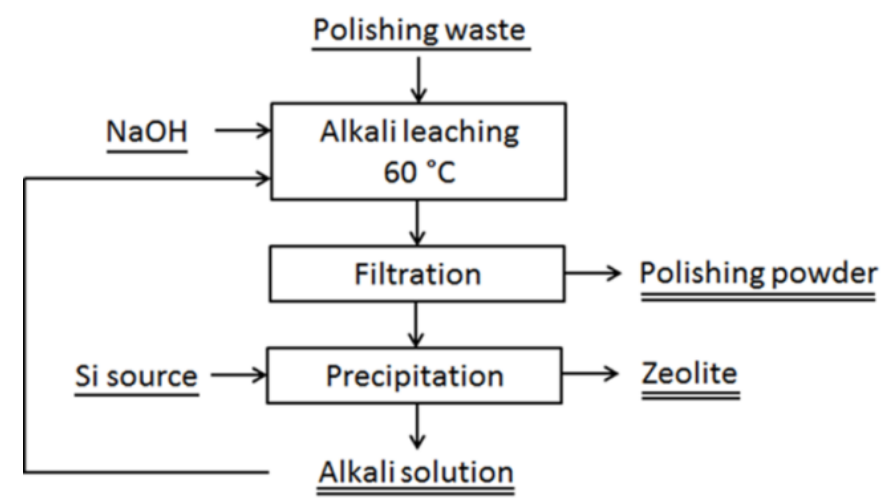

Figure 6. Alkali leaching of polishing powder for the recovery of polishing powder followed by recovery of silica and alumina as zeolite from leach solution. Adapted from Kato et al. [12], with permission from American Chemical Society, 2018. 
Table 4. Different studies on recovery and recycling of rare earths from glass polishing waste by using physical, chemical and/or physico-chemical processes.

\begin{tabular}{|c|c|c|c|}
\hline Physical or Physio-Chemical Separation & Chemical Separation & Recovery of REEs/Reuse of Polishing Powder & Reference \\
\hline $\begin{array}{l}\text { Coarse glass particles: sieving } \\
\text { Filtration with vibrating screen }\end{array}$ & & Product: for reuse in polishing & [40] \\
\hline $\begin{array}{c}\text { Elutriation } \\
\text { Rapid settling: glass } \\
\text { Slow settling (3 days): rare earths }\end{array}$ & & Product: for reuse in polishing & [40] \\
\hline Flotation: dodecylesulfate (collector) & & $40 \%$ with a purity of $44 \%$ ( $35 \%$ in feed sample) & [40] \\
\hline Flotation & $\begin{array}{l}\mathrm{HCl}\left(1.4 \mathrm{kmol} / \mathrm{m}^{3}\right) 55^{\circ} \mathrm{C}, 60 \mathrm{~min} \\
\text { Selective Ce leaching }\end{array}$ & $\begin{array}{l}\text { D2EHPA and PC-88ACe recovered } \\
\text { preferentially over La }\end{array}$ & [40] \\
\hline \multirow[t]{6}{*}{$\begin{array}{l}\text { Flocculent removal: } \\
\text { oxalic or citric acid leaching (pH-1.5) } \\
\text { Silica removal: } \\
\text { flotation aided by sonication }\end{array}$} & $\begin{array}{c}\text { Silica: } \\
\text { alkali leaching }(\mathrm{pH}-11.5) \\
\text { Roasting: } 600^{\circ} \mathrm{C}, 2 \mathrm{~h} \\
\text { Rare earths: } \\
\text { Sulfuric acid }(3 \mathrm{~mol} / \mathrm{L}), \mathrm{S} / \mathrm{L}-1: 10,60^{\circ} \mathrm{C}, 3 \mathrm{~h}\end{array}$ & $\begin{array}{l}\text { Other rare earths: Double sulfate precipitation, } \\
\qquad \mathrm{Na}_{2} \mathrm{SO}_{4} / \mathrm{REO}-0.5 \text { to } 1 \\
\text { Ce Yield: } 60 \%\end{array}$ & {$[29,30]$} \\
\hline & $\begin{array}{c}\mathrm{NaOH}: 4 \mathrm{~mol} / \mathrm{kg}, 1 \mathrm{~h} \\
50-60^{\circ} \mathrm{C}\end{array}$ & $\begin{array}{l}\text { Residue: for reuse in polishing } \\
\text { Aluminum and silicon in the leach solution were } \\
\text { recovered as zeolites }\end{array}$ & {$[12,41]$} \\
\hline & $\begin{array}{c}\text { Alkali Leaching } \\
\mathrm{NaOH}, \mathrm{NaF}, \mathrm{Na}_{2} \mathrm{CO}_{3} \\
90{ }^{\circ} \mathrm{C}, 2 \mathrm{~h}\end{array}$ & Residue: for reuse in polishing & [20] \\
\hline & $\begin{array}{l}\mathrm{NaOH}(2 \mathrm{~mol} / \mathrm{L}) \\
\mathrm{KOH}(3.5 \mathrm{~mol} / \mathrm{L})\end{array}$ & Residue: for reuse in polishing & [13] \\
\hline & $\begin{array}{c}\text { HCl: } 15-35 \mathrm{wt} \%(10-20 \% \text { excess }) . \\
\text { Iodide: } 10-20 \% \text { excess } \\
15-60 \mathrm{~min}\end{array}$ & & {$[42]$} \\
\hline & $\begin{array}{c}\mathrm{HNO}_{3} \text { and } \mathrm{H}_{2} \mathrm{O}_{2} \\
\mathrm{H}_{2} \mathrm{O}_{2} / \mathrm{HNO}_{3}=0.15 \\
80^{\circ} \mathrm{C}, \mathrm{S} / \mathrm{L}: 1: 5\end{array}$ & $\begin{array}{l}\text { RE recovery: } 80 \% \\
\text { Precipitation with ammonium carbonate }\end{array}$ & [43] \\
\hline
\end{tabular}


Table 4. Cont.

\begin{tabular}{|c|c|c|c|}
\hline Physical or Physio-Chemical Separation & Chemical Separation & Recovery of REEs/Reuse of Polishing Powder & Reference \\
\hline & \multicolumn{2}{|c|}{$\begin{array}{c}\text { Pure oxides } \\
\text { Step 1: } 0.4 \mathrm{~mol} / \mathrm{L} \mathrm{Na}_{2} \mathrm{SO}_{4} \text { and } 8 \mathrm{~mol} / \mathrm{L} \mathrm{H}_{2} \mathrm{SO}_{4} \text { for double salt precipitation } \\
\text { Step 2: } \mathrm{RE} \text { hydroxide precipitation from double salt with } \mathrm{NaOH} \\
\text { Step 3: Oxidation of cerium } \\
\text { Step 4: } \mathrm{HCl}(\text { selective) leaching of rare earths except cerium } \\
\text { Step 5: } \mathrm{H}_{2} \mathrm{SO}_{4} \text { (selective) leaching of cerium }\end{array}$} & [44-46] \\
\hline \multicolumn{3}{|c|}{$\begin{array}{c}\text { Pure oxides } \\
\mathrm{H}_{2} \mathrm{SO}_{4}\left(1-8 \mathrm{~mol} / \mathrm{dm}^{3}\right), 30-90{ }^{\circ} \mathrm{C} \\
\end{array}$} & [37] \\
\hline & $\begin{array}{c}\mathrm{HCl}: 32 \mathrm{wt} \%, \mathrm{H}_{2} \mathrm{O}_{2}: 30 \mathrm{wt} \% \\
80{ }^{\circ} \mathrm{C}, 4 \mathrm{~h} \\
\text { Ce recovery }(>90 \%), \text { La recovery }(>60 \%)\end{array}$ & \multirow[t]{3}{*}{ Oxalic acid ( $27 \%$ excess) precipitation } & \multirow[t]{3}{*}{ [24-26] } \\
\hline & $\begin{array}{c}\mathrm{HNO}_{3}: 47 \%, \mathrm{H}_{2} \mathrm{O}_{2}: 30 \mathrm{wt} \% \\
70^{\circ} \mathrm{C}, 1 \mathrm{~h} \\
\text { Ce recovery }(>90 \%), \text { La recovery }(>60 \%)\end{array}$ & & \\
\hline & $\begin{array}{c}\mathrm{H}_{2} \mathrm{SO}_{4}: 98 \%, 100-200{ }^{\circ} \mathrm{C} \\
\text { followed by water leaching } \\
\text { Ce, La recovery }(>90 \%)\end{array}$ & & \\
\hline & $\begin{array}{c}\mathrm{HNO}_{3} \text { and } \mathrm{H}_{2} \mathrm{O}_{2}: 20 \% \text { excess (with respect } \\
\text { to the total REE content) } \\
70^{\circ} \mathrm{C}, 3 \mathrm{~h}\end{array}$ & $\begin{array}{l}\text { Carbonate precipitation by } \mathrm{CO}_{2} \text { and } \mathrm{NH}_{3} \\
\text { followed by annealing in rotary kiln }\end{array}$ & [23] \\
\hline & $\begin{array}{c}\mathrm{HNO}_{3} \text { and } \mathrm{H}_{2} \mathrm{O}_{2} \text { (stoichiometric) } \\
\qquad 80^{\circ} \mathrm{C}\end{array}$ & Oxalate precipitation & [27] \\
\hline & $\begin{array}{c}\text { Carbochlorination: Active carbon, } \mathrm{N}_{2}-\mathrm{Cl}_{2} \\
\text { gas, } 1000^{\circ} \mathrm{C},\end{array}$ & $\begin{array}{l}\text { Rare earth chloride deposition: }<1000{ }^{\circ} \mathrm{C} \text { to } 450 \\
{ }^{\circ} \mathrm{C} \text {. }\end{array}$ & {$[21,22]$} \\
\hline & $\begin{array}{c}\text { Sulfation: } \mathrm{H}_{2} \mathrm{SO}_{4}, 250{ }^{\circ} \mathrm{C}, 2 \mathrm{~h} \\
\text { Water leaching } \\
50^{\circ} \mathrm{C}, 2 \mathrm{~h}, \mathrm{~L} / \mathrm{S}: 10\end{array}$ & Double sulfate precipitation & [47] \\
\hline
\end{tabular}


Removal of glass particles by sieving, flotation, and/or alkali leaching can increase the lifespan of polishing powder to some extent [23]. However, the removal of silica and/or alumina alone is insufficient as the increase in concentration of other elements like zinc, calcium, sodium, etc. adversely affects the product quality after several cycles [25]. The main problem with alkali leaching is that it needs large scale facilities and generate high volumes of alkaline waste water [40]. Therefore, complete removal of impurities or dissolution of cerium into the leach solution followed by cerium recovery is required. This will be described and discussed in Section 3.2.2 (acid leaching) and Section 3.2.3 (REEs recovery).

\subsubsection{Acid Leaching—for REE Recovery}

\section{Direct Leaching}

Cerium dioxide is sparingly soluble in most of the acids at ambient conditions [48]. The solubility of $\mathrm{CeO}_{2}$ in acids solutions is further reduced due to the high temperature sintering (annealing) at 600 to $1000^{\circ} \mathrm{C}$ of the powder before its application in polishing [23]. Therefore, leaching needs to be carried out in concentrated acid solutions and/or at elevated temperatures. Different acids such as $\mathrm{HCl}, \mathrm{HNO}_{3}, \mathrm{H}_{2} \mathrm{SO}_{4}$ and $\mathrm{HF}$ can be used for leaching of glass polishing waste. HF acid can be used for removal of silica. However, it has some disadvantages like residual HF, which reacts with the glass surface and roughen the surface during polishing, and HF is also hazardous [13]. Sulfuric acid is a low cost reagent and less corrosive. However, the solubility of rare-earth sulfates is very low in leach solutions and the solubility decreases with increasing the temperature. The decrease in solubility is due to the exothermic nature of the rare-earth sulfate dissolution $[29,37]$. In the following, four different direct leaching methods are briefly discussed.

- Concentrated $\mathrm{H}_{2} \mathrm{SO}_{4}$ leaching: After removal of silica from glass polishing waste by flotation and after alkali leaching, Kim et al. performed oxidative roasting on dried samples at $600{ }^{\circ} \mathrm{C}$ to convert cerium compounds to $\mathrm{CeO}_{2}$ [29]. Cerium was leached from the roasted mass by concentrated sulfuric acid solution at $60^{\circ} \mathrm{C}$. These authors claimed that high amount of oxidation of cerium oxide dissolves more cerium in to the leach solution. However, for a small increase in cerium recovery (about 10\%) the roasting of the powder is difficult to be justified.

- Concentrated $\mathrm{H}_{2} \mathrm{SO}_{4}$ digestion-water leaching: Poscher et al. [25] digested polishing powder with conc. sulfuric acid ( $>96 \mathrm{wt} \%$ ) at temperatures above $100{ }^{\circ} \mathrm{C}$. During digestion the slurry was solidified. The digested material was subsequently leached with water to dissolve rare earth sulfates.

- Two stage $\mathrm{H}_{2} \mathrm{SO}_{4}$ leaching: Um et al. leached a synthetic mixture with sulfuric acid in two stages for selective recovery of cerium [37]. In the first stage, the mixture was treated with $2 \mathrm{~mol} / \mathrm{dm}^{3}$ sulfuric acid at $90{ }^{\circ} \mathrm{C}$ for leaching $\mathrm{La}, \mathrm{Nd}, \mathrm{Pr}$ and $\mathrm{Ca}$. In the second stage, the leach residue from first stage was treated with $12 \mathrm{~mol} / \mathrm{dm}^{3}$ and $120^{\circ} \mathrm{C}$. After leaching, the leach solution was diluted with water to dissolve $\mathrm{Ce}\left(\mathrm{SO}_{4}\right)_{2}$.

- $\mathrm{HCl}$ leaching: Yamada et al. [40] were able to recover cerium selectively by using $1.4 \mathrm{kmol} / \mathrm{m}^{3} \mathrm{HCl}$ at $55{ }^{\circ} \mathrm{C}$. The recovery of cerium is about $65 \%$ and that of lanthanum is very low. From this study it looks that cerium can be selectively dissolved. However, the recovery of cerium or lanthanum mainly depends on the presence of different compounds [25]. For example, if the lanthanum is present in a fluoride phase then it is difficult to dissolve. However, part of lanthanum in oxyfluoride may dissolve during leaching according to the following reaction.

$$
\mathrm{LaO}_{0.65} \mathrm{~F}_{1.7}+1.3 \mathrm{HCl} \rightleftharpoons 0.433 \mathrm{LaCl}_{3}+0.566 \mathrm{LaF}_{3}+0.65 \mathrm{H}_{2} \mathrm{O}
$$

The recovery of cerium and/or lanthanum in some studies is low due to the fact that part of the cerium and lanthanum are present in stable compounds like fluorides or phosphates. 
Acid Leaching Together with a Reductant

As discussed earlier, leaching of $\mathrm{CeO}_{2}$ directly is difficult. Therefore, the use of a reductant can help for easier dissolution and in decreasing the acid concentration and leaching temperature. Potassium iodide [42] and $\mathrm{H}_{2} \mathrm{O}_{2}$ [23-25,27] are used as reductants during acid leaching of glass polishing waste so far. The reaction involved during the reductive leaching of $\mathrm{CeO}_{2}$ with $\mathrm{H}_{2} \mathrm{O}_{2}$ is

$$
2 \mathrm{Ce}^{4+}+\mathrm{H}_{2} \mathrm{O}_{2} \rightleftharpoons 2 \mathrm{Ce}^{3+}+2 \mathrm{H}^{+}+\mathrm{O}_{2}
$$

Poscher et al. leached the polishing waste with $\mathrm{HCl}$ and $\mathrm{H}_{2} \mathrm{O}_{2}$. More than $97 \%$ of cerium was recovered by using concentrated acid [24]. These authors proposed that the lanthanum leaching is low due to the presence of fluorine compounds. The optimized conditions are: liquid-to-solid ratio of 5.5, acid concentration of $32 \%$ at $80{ }^{\circ} \mathrm{C}$ for $4 \mathrm{~h}$ duration.

An industrial process was developed by Hydrometal, Belgium for the recovery of cerium from glass polishing waste by reductive leaching of glass polishing powder with nitric acid together with $\mathrm{H}_{2} \mathrm{O}_{2}$ [27]. The flowsheet developed by Hydrometal is shown in Figure 7. The $\mathrm{Ce}^{4+}$ concentration in the leach solution was monitored during leaching using ORP (oxidation/reduction potential) detector. Nitric acid was used as a lixiviant as it is selective towards silica and alumina. The authors used a higher temperature $\left(\sim 80^{\circ} \mathrm{C}\right)$ for the diffusion of the acid in to silica matrix and also for enhancing filtration.

Janoš et al. [49] were able to leach the glass polishing waste $\left(\sim 60 \% \mathrm{CeO}_{2}\right)$ in nitric acid and $\mathrm{H}_{2} \mathrm{O}_{2}$ solution without any external heating. However, with low cerium content $(\sim 9 \%)$ the external heating is necessary to maintain the temperature $\left(65-70{ }^{\circ} \mathrm{C}\right)$ [23]. The leaching recovery of cerium was around $70 \%$. In an another study, Janoš et al. [42] studied the leaching of polishing waste with hydrochloric acid and potassium iodide. $15-35 \% \mathrm{HCl}$ was added together with $10-20 \%$ excess of potassium iodide during leaching. These authors claimed that the leaching was complete in 15-60 min.

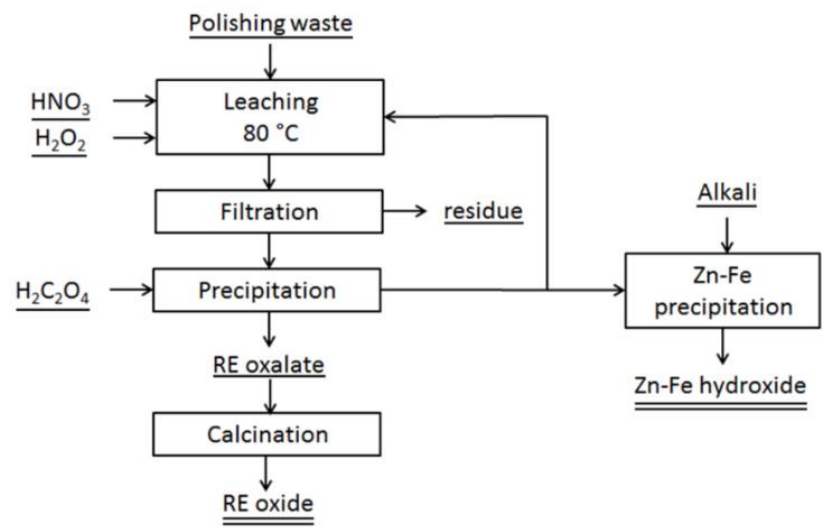

Figure 7. Flowsheet developed by Hydrometal for recovery of rare earth oxides from polishing waste by leaching followed by selective precipitation. Adapted from Henry et al. [27].

\subsubsection{Recovery of REEs from Polishing Waste Leach Solutions}

Different methods that are used for the recovery of cerium from a leach solution include: double salt precipitation, oxalate precipitation, carbonate precipitation, hydroxide precipitation and solvent extraction followed by precipitation. Separation of individual REEs from a mixture is difficult due to the similar physical and chemical properties. Separation of rare earths are generally carried out by solvent extraction using following steps: (1) rare earth separation in a trivalent state, (2) separation of rare earths into three or four groups, (3) selective recovery of cerium using its tetravalent state, (4) separation of the desired individual rare earth of required purity [1,50].

Lanthanum and cerium are next to each other in the periodic table and their stability constants are very close, therefore their complexation behavior is also very similar [51]. Hence, it is difficult to separate them completely in trivalent state as hundreds of stages of mixers and settlers are required in 
solvent extraction. Nevertheless, cerium separation is the easiest as it can be oxidized to tetravalent state, which has different chemical properties compared to trivalent rare-earth ions. Figure 8 shows the individual and overlapped cerium and lanthanum Pourbaix diagrams. The overlapped Pourbaix diagram shows a window where cerium can be selectively precipitated by keeping lanthanum in the solution [52]. However, in a recent study, Marsac et al. found more accurate hydrolysis constants for cerium system [53]. This may slightly change the stability regions of different species in cerium Pourbaix diagram.

Cerium can be oxidized and precipitated as tetravalent state in alkaline solution even with air [29]. Other oxidants that may convert Ce(III) to Ce(IV) are persulfate, permanganate, lead oxide, silver oxide or by electrochemical or photochemical oxidation [29].

Poscher et al. precipitated cerium and lanthanum from the solution by $27 \%$ excess oxalic acid addition [24]. The precipitated oxalates are calcined at $650{ }^{\circ} \mathrm{C}$ to convert oxalates to respective oxides. The solution obtained after oxalic acid precipitation is reused in leaching, after impurity removal by precipitation [27]. Poscher et al. proposed to selectively precipitate cerium from solution with an oxidizing treatment and $\mathrm{pH}$ adjustment [24]. This oxidizing agents include $\mathrm{H}_{2} \mathrm{O}_{2}$ or potassium permanganate. However, oxidants other than $\mathrm{H}_{2} \mathrm{O}_{2}$ may contaminate the product with the reaction product of the oxidizing agents [24,29]. After cerium removal by oxidation, lanthanum can be removed by oxalic acid treatment. Cerium was also recovered from the solution by a mixture of $\mathrm{CO}_{2}$ and $\mathrm{NH}_{3}$ [23]. The obtained carbonate can be converted to oxide by calcination from 200 to $900{ }^{\circ} \mathrm{C}$. The carbonate can also be prepared by precipitation of an aqueous solution of cerous nitrate $(0.2 \mathrm{~mol} / \mathrm{L})$ with an excess of ammonium bicarbonate $\left(0.5 \mathrm{~mol} \mathrm{NH}_{4} \mathrm{HCO}_{3} / \mathrm{L}\right)$ [54].
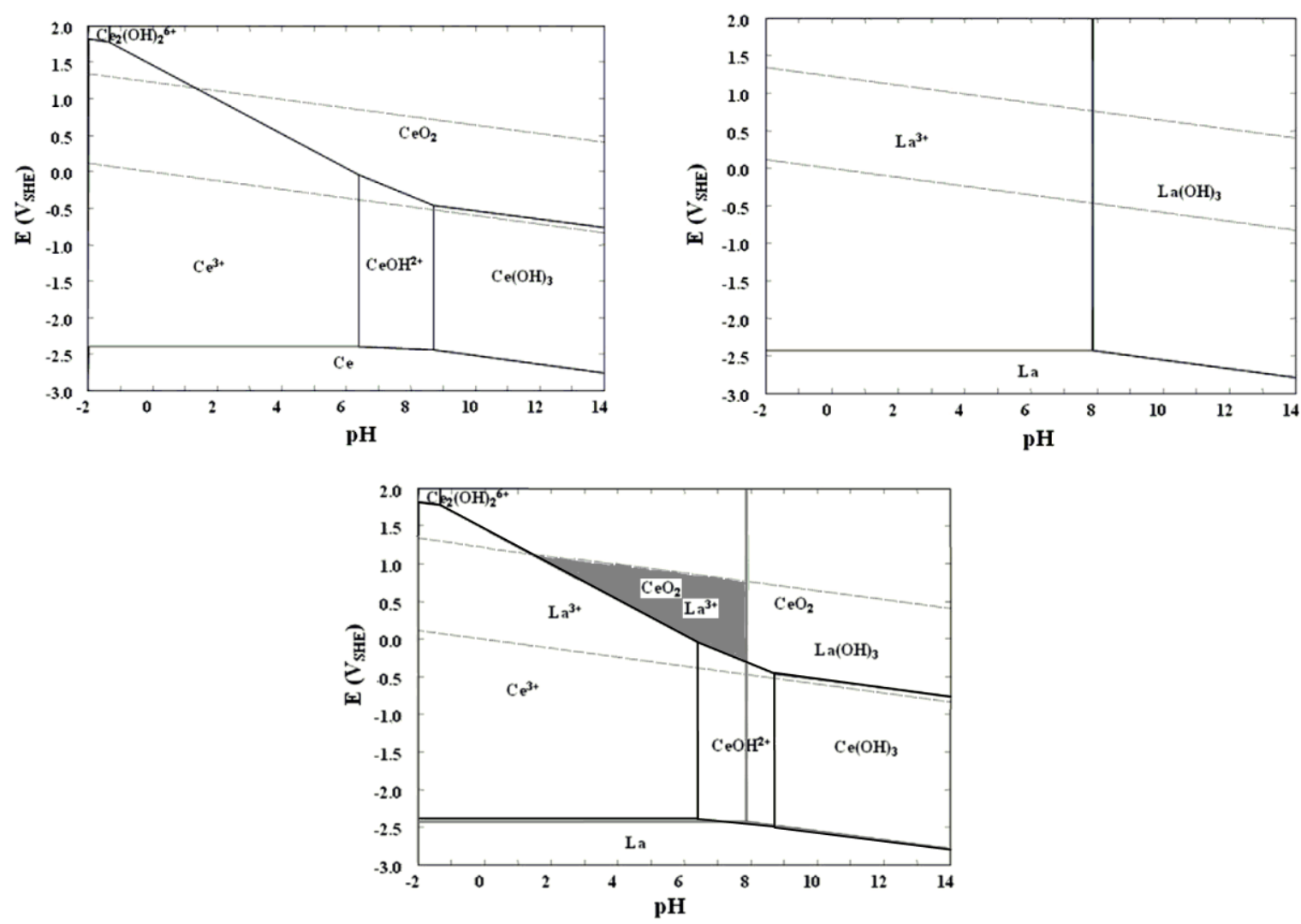

Figure 8. Individual and overlapped Pourbaix diagrams of cerium and lanthanum. The overlapped Pourbaix diagram of lanthanum (gray lines) and cerium (black lines) show the region where cerium can be selectively precipitated in aqueous solutions. La and Ce concentrations are $10^{-3} \mathrm{~mol} / \mathrm{L}$ each. Reproduced and adapted from Kim and Osseo-Asare [52], with permission from Elsevier, 2018. 
Kim et al. [29] removed other REEs from cerium by double sulfate precipitation with sodium sulfate at $50{ }^{\circ} \mathrm{C}$ and $90 \mathrm{~min}$. The authors were able to recover over $62 \%$ cerium in solution at $\mathrm{Na}_{2} \mathrm{SO}_{4} / \mathrm{RE}$ ratio of 0.5 with $\mathrm{La} / \mathrm{Ce}$ ratio of 0.0307 . Yoon et al. separated rare earths from aluminum by double salt precipitation with $\mathrm{Na}_{2} \mathrm{SO}_{4}$ at $50{ }^{\circ} \mathrm{C}$ for $1 \mathrm{~h}$ [47]. Um and Hirato precipitated $\mathrm{NaCe}\left(\mathrm{SO}_{4}\right)_{2} \cdot \mathrm{xH}_{2} \mathrm{O}$ from $\mathrm{CeO}_{2}$ by sulfuric acid leaching in presence of $\mathrm{Na}_{2} \mathrm{SO}_{4}$ at about $125{ }^{\circ} \mathrm{C}[46,48]$. In another study, $\mathrm{Um}$ and Hirato proposed to produce rare earth hydroxide from $\mathrm{NaCe}\left(\mathrm{SO}_{4}\right)_{2} \cdot \mathrm{xH}_{2} \mathrm{O}$ with the help of $\mathrm{NaOH}$ followed by oxidation of $\mathrm{Ce}(\mathrm{OH})_{3}$ to $\mathrm{Ce}(\mathrm{OH})_{4}$. In the next step, the authors proposed to leach rare earths other than $\mathrm{Ce}$ at higher $\mathrm{pH}$ values (2.5 to 3.5). Cerium with high selectivity was leached in the following step with sulfuric acid [44].

Yamada et al. [40] extracted cerium preferentially over lanthanum using D2EHPA and PC-88A reagents. The authors were able to extract cerium selectively with $50 \%$ PC-88A at pH 1.24 with a selectivity of about 2.5 .

\subsubsection{Other Processes for REE Recovery}

Ozaki et al. separated cerium and other REEs from glass polishing waste by a chemical transport method [21,22]. $\mathrm{A} \mathrm{Cl}_{2}-\mathrm{N}_{2}$ gaseous mixture was used for carbo-chlorination together with active carbon. The following reactions of cerium and other lanthanides $(\mathrm{Ln})$ takes place during the carbochlorination:

$$
\begin{aligned}
& \mathrm{Ln}_{2} \mathrm{O}_{3}+2 \mathrm{C}+3 \mathrm{Cl}_{2} \rightleftharpoons 2 \mathrm{LnCl}_{3}+3 \mathrm{CO} \\
& 2 \mathrm{CeO}_{2}+4 \mathrm{C}+3 \mathrm{Cl}_{2} \rightleftharpoons 2 \mathrm{CeCl}_{3}+4 \mathrm{CO}
\end{aligned}
$$

After chloride conversion, rare-earth chlorides were exposed to $\mathrm{Al}_{2} \mathrm{Cl}_{6}$ gas to form low volatile $\left(\mathrm{LnAl}_{3} \mathrm{Cl}_{12}\right)$ complexes. At low temperatures $\left(457-947^{\circ} \mathrm{C}\right)$ these complexes dissociates and forms rare-earth chlorides. By this process RE chlorides were successfully separated from CO gas and other chlorides. However, it is difficult to separate individual REEs, because of their similar chemical properties due to same oxidation state and similar ionic radii.

Yoon et al. developed a sulfation process to convert (decompose) rare earth compounds in the polishing waste to their respective sulfates at $250{ }^{\circ} \mathrm{C}$ in presence of sulfuric acid [47]. The sulfated roast was leached in water at $50{ }^{\circ} \mathrm{C}$ and able to recover rare earths completely. Wang et al. studied the sulfation process using TGA and FTIR [28]. The recovery yield in their process was about $95 \%$. These authors found that rare earth oxides decompose at $250^{\circ} \mathrm{C}$ and rare earth oxyfluorides decompose at $300{ }^{\circ} \mathrm{C}$. The temperature in TGA is higher for complete decomposition when compared to the study of Yoon et al. This difference may be due to non-isothermal heating used in TGA.

\section{Applications of Recovered Cerium}

Large quantities of cerium can be generated by treating the current glass polishing waste and waste from landfills. Currently, the recovered cerium is reused in polishing process [36]. However, the recovered cerium can also be used in other applications such as redox flow batteries, oxidimetric agent and as a catalyzer [37]. Janoš et al. [54] transformed polishing powder waste into phosphor elimination adsorption material, which could effectively eliminate the phosphate in sewage. The recovered cerium can also be used for preparing valuable Al-Ce alloys [32]. Cerium as an alloying element in aluminum increases the strength at room temperature as well as at high temperature. Hence, these alloys can be used for IC engines. These engines with Al-Ce alloys can be operated at higher temperatures that increase the fuel efficiency. Application of cerium in aluminum alloys can also address the so-called balance problem [32].

\section{Conclusions}

Large quantities of cerium in glass polishing waste are being lost in landfills. The life of glass polishing waste can be increased by removing silica with physical beneficiation and/or alkali leaching processes. However, it is difficult to remove silica completely by physical beneficiation processes 
alone. Silica and alumina can be removed from polishing waste by alkali leaching. Nevertheless, an increase in the concentration of impurities other than alumina and silica affects the polishing process, and thus complete removal of impurities is required. Another alternative is to recover all REEs as oxides or RE metals/alloys from the polishing waste. Cerium and other REEs can be recovered from glass polishing waste by acid leaching processes followed by extraction from leach solutions. However, high acid concentration and/or temperatures or costly reagents (reductants) are required during leaching. Furthermore, part of cerium and/or lanthanum are present in the form of fluoride and phosphates and they report to residue during leaching. Hence, an extra processing step is required for complete recovery of rare earths. Cerium can be extracted from solution by precipitation or separated by solvent extraction. The extracted cerium can be used in glass polishing or other high value added applications.

Author Contributions: C.R.B. prepared the manuscript. All authors discussed and reviewed the manuscript.

Funding: This research was funded TU Delft (3mE Cohesie project: "Sustainable Rare-earth Cycle") and NWO-CW (VICI grant).

Conflicts of Interest: The authors declare no conflict of interest.

\section{References}

1. Krishnamurthy, N.; Gupta, C.K. Extractive Metallurgy of Rare Earths; CRC Press: Boca Raton, FL, USA, 2015; ISBN 1466576383.

2. Gambogi, J. Rare earths. In Mineral Commodity Summeries; USGS: Reston, VA, USA, 2018; pp. $132-133$.

3. Jha, M.K.; Kumari, A.; Panda, R.; Kumar, J.R.; Yoo, K.; Lee, J.Y. Review on hydrometallurgical recovery of rare earth metals. Hydrometallurgy 2016, 165, 2-26. [CrossRef]

4. Guyonnet, D.; Planchon, M.; Rollat, A.; Escalon, V.; Tuduri, J.; Charles, N.; Vaxelaire, S.; Dubois, D.; Fargier, H. Material flow analysis applied to rare earth elements in Europe. J. Clean. Prod. 2015, 107, 215-228. [CrossRef]

5. Binnemans, K.; Jones, P.T.; Blanpain, B.; Van Gerven, T.; Yang, Y.; Walton, A.; Buchert, M. Recycling of rare earths: A critical review. J. Clean. Prod. 2013, 51, 1-22. [CrossRef]

6. Gambogi, J. USGS 2014 Minerals Yearbook: Rare Earths; USGS: Reston, VA, USA, 2016.

7. Argus Media Analysing the Changing Global Rare Earths Supply and Demand Outlook. Available online: http:/ / www.argusmedia.jp/ /media/files/pdfs/regional-specific/jp/downloads/argus-metalpages-forum082016-rareearths.pdf/?la=en (accessed on 16 February 2017).

8. Tercero Espinoza, L.; Hummen, T.; Brunot, A.; Hovestad, A.; Peña Garay, I.; Velte, D.; Smuk, L.; Todorovic, J.; Van Der Eijk, C.; Joce, C. Critical Raw Materials Substitution Profiles; CRM InnoNet: Karlsruhe, Germany, 2015.

9. Lucas, J.; Lucas, P.; Le Mercier, T.; Rollat, A.; Davenport, W.; Le Mercier, T.; Rollat, A.; Davenport, W. Chapter 12-Polishing with Rare Earth Oxides Mainly Cerium Oxide $\mathrm{CeO}_{2}$. In Rare Earths; Elsevier: Amsterdam, The Netherlands, 2015; pp. 191-212. ISBN 978-0-444-62735-3.

10. Cook, L.M. Chemical processes in glass polishing. J. Non-Cryst. Solids 1990, 120, 152-171. [CrossRef]

11. Hedrick, J.B.; Sinha, S.P. Cerium-based polishing compounds: Discovery to manufacture. J. Alloys Compd. 1994, 207-208, 377-382. [CrossRef]

12. Kato, K.; Yoshioka, T.; Okuwaki, A. Study for recycling of ceria-based glass polishing powder. Ind. Eng. Chem. Res. 2000, 39, 943-947. [CrossRef]

13. Matsui, H.; Harada, D.; Takeuchi, M. Method for Recovery of Cerium Oxide. U.S. Patent 20130152483A1, 20 June 2013.

14. $\mathrm{Xu}, \mathrm{T}$.; Peng, H. Formation cause, composition analysis and comprehensive utilization of rare earth solid wastes. J. Rare Earths 2009, 27, 1096-1102. [CrossRef]

15. Janoš, P.; Ederer, J.; Pilařová, V.; Henych, J.; Tolasz, J.; Milde, D.; Opletal, T. Chemical mechanical glass polishing with cerium oxide: Effect of selected physico-chemical characteristics on polishing efficiency. Wear 2016, 362-363, 114-120. [CrossRef]

16. Komiya, H.; Yamaguchi, S.; Hisatsune, T.; Takenaka, A.; Yonemori, S. Method for Evaluating the Quality of Abrasive Grains, Polishing Method and Abrasive for Polishing Glass. U.S. Patent 7025796B2, 11 April 2006.

17. Ikeda, H.; Akagami, Y. Highly efficient polishing technology for glass substrates using tribo-chemical polishing with electrically controlled slurry. J. Manuf. Process. 2013, 15, 102-107. [CrossRef] 
18. Kaller, A. The basic mechanism of glass polishing. Naturwissenschaften 2000, 87, 45-47. [CrossRef] [PubMed]

19. Kasai, T.; Bhushan, B. Physics and tribology of chemical mechanical planarization. J. Phys. Condens. Matter 2008, 20, 225011-225023. [CrossRef]

20. Moon, W.-J.; Na, S.-O.; Oh, H.-Y. Method for Recycling Cerium Oxide Abrasive. U.S. Patent 20110219704A1, 15 September 2011.

21. Ozaki, T.; Machida, K.; Adachi, G. Recovery of rare earths from used polishes by chemical vapor transport process. Mater. Sci. Forum 1999, 315-317, 297-305. [CrossRef]

22. Ozaki, T.; Machida, K.; Adachi, G. Extraction and mutual separation of rare earths from used polishes by chemical vapor transport. Metall. Mater. Trans. B 1999, 30, 45-51. [CrossRef]

23. Janoš, P.; Kuráň, P.; Ederer, J.; Šastný, M.; Vrtoch, L.; Pšenička, M.; Henych, J.; Mazanec, K.; Skoumal, M. Recovery of Cerium Dioxide from Spent Glass-Polishing Slurry and Its Utilization as a Reactive Sorbent for Fast Degradation of Toxic Organophosphates. Adv. Mater. Sci. Eng. 2015, 2015, 241421. [CrossRef]

24. Poscher, A.; Luidold, S.; Antrekowitsch, H. Extraction of cerium and lanthanum from spent glass polishing agent. In Materials Science \& Technology 2013; London, I.M., Goode, J.R., Moldoveanu, G., Rayat, M.S., Eds.; Canadian Institute of Mining, Metallurgy and Petroleum: Montréal, QC, Canada, 2013; pp. 543-552.

25. Poscher, A.; Luidold, S.; Schnideritsch, H.; Antrekowitsch, H. Extraction of Lanthanides from Spent Polishing Agent. In Proceedings of the ERES2014-1st European Rare Earth Resources Conference, Milos, Greece, 4-7 September 2014; pp. 209-222.

26. Poscher, A.; Luidold, S.; Schnideritsch, H.; Antrekowitsch, H. Extraction of Lanthanides from Spent Polishing Agent; Elsevier Inc.: San Diego, CA, USA, 2015; ISBN 9780128023280.

27. Henry, P.; Lamotte, S.; Bier, J. Recycling of rare earth materials at Hydrometal (Belgium). In 52nd Conference of Metallurgists (COM), Hosting by Materials Science Technology Conference (MSET); London, I.M., Goode, J.R., Moldoveanu, G., Rayat, M.S., Eds.; Canadian Institute of Mining, Metallurgy and Petroleum: Montréal, QC, Canada, 2013; pp. 537-542.

28. Wang, X.; Liu, J.; Yang, Q.; Du, J.; Wang, F.; Tao, W. Decomposition process and kinetics of waste rare earth polishing powder TG-DTA-FTIR studies. J. Therm. Anal. Calorim. 2012, 109, 419-424. [CrossRef]

29. Kim, J.Y.; Kim, U.S.; Byeon, M.S.; Kang, W.K.; Hwang, K.T.; Cho, W.S. Recovery of cerium from glass polishing slurry. J. Rare Earths 2011, 29, 1075-1078. [CrossRef]

30. Byeon, M.S.; Kim, J.Y.; Hwang, K.T.; Kim, U.; Cho, W.S.; Kang, W.K. Recovery and purification of cerium from glass polishing slurry. In Proceedings of the 18th International Conference on Composite Materials, Jeju, Korea, 21-26 August 2011.

31. Kumar, V.; Jha, M.K.; Kumari, A.; Panda, R.; Kumar, J.R.; Lee, J.Y. Recovery of Rare Earth Metals (REMs) from Primary and Secondary Resources: A Review. In Rare Metal Technology 2014; Neale, R., Neelameggham, N.R., Alam, S., Oosterhof, H., Jha, A., Wang, S., Eds.; Wiley: San Diego, CA, USA, 2014; pp. 81-88.

32. Sims, Z.C.; Weiss, D.; McCall, S.K.; McGuire, M.A.; Ott, R.T.; Geer, T.; Rios, O.; Turchi, P.A.E. Cerium-Based, Intermetallic-Strengthened Aluminum Casting Alloy: High-Volume Co-product Development. JOM 2016, 68, 1940-1947. [CrossRef]

33. Willbold, E.; Gu, X.; Albert, D.; Kalla, K.; Bobe, K.; Brauneis, M.; Janning, C.; Nellesen, J.; Czayka, W.; Tillmann, W. Effect of the addition of low rare earth elements (lanthanum, neodymium, cerium) on the biodegradation and biocompatibility of magnesium. Acta Biomater. 2015, 11, 554-562. [CrossRef] [PubMed]

34. Pan, F.; Zhang, J.; Chen, H.-L.; Su, Y.-H.; Kuo, C.-L.; Su, Y.-H.; Chen, S.-H.; Lin, K.-J.; Hsieh, P.-H.; Hwang, W.-S. Effects of rare earth metals on steel microstructures. Materials 2016, 9, 1-19. [CrossRef] [PubMed]

35. Lucas, J.; Lucas, P.; Le Mercier, T.; Rollat, A.; Davenport, W. Epilogue. In Rare Earths; Elsevier: Amsterdam, The Netherlands, 2015; pp. 351-362. ISBN 9780444627353.

36. Lucas, J.; Lucas, P.; Le Mercier, T.; Rollat, A.; Davenport, W. Chapter 18-Rare Earth Recycle; Elsevier: Amsterdam, The Netherlands, 2015; pp. 333-350. [CrossRef]

37. Um, N.; Hirato, T. Dissolution Behavior of $\mathrm{La}_{2} \mathrm{O}_{3}, \mathrm{Pr}_{2} \mathrm{O}_{3}, \mathrm{Nd}_{2} \mathrm{O}_{3}, \mathrm{CaO}$ and $\mathrm{Al}_{2} \mathrm{O}_{3}$ in Sulfuric Acid Solutions and Study of Cerium Recovery from Rare Earth Polishing Powder Waste via Two-Stage Sulfuric Acid Leaching. Mater. Trans. 2013, 54, 713-719. [CrossRef]

38. Lebedeva, M.I.; Dzidziguri, E.L.; Argatkina, L.A. Research of structure and polishing properties of nanopowders based on cerium dioxide. In Nanostructures, Nanomaterials, and Nanotechnologies to Nanoindustry; Apple Academic Press: Waretown, NJ, USA, 2014; pp. 215-225. 
39. Borra, C.R.; Vlugt, T.J.; Yang, Y.; Offerman, S.E. Characterisation of glass polishing waste samples. In Proceedings of the ERES 2017: The Second Conference on European Rare Earth Resources, Santorini, Greece, 28-31 May 2017; pp. 215-216.

40. Tanaka, M.; Oki, T.; Koyama, K.; Narita, H.; Oishi, T. Recycling of Rare Earths from Scrap, 1st ed.; Elsevie: Amsterdam, The Netherlands, 2013; Volume 43, ISBN 9780444595362.

41. Kato, K.; Yoshioka, T.; Okuwaki, A. Recyle of Ceria-Based Glass Polishing Powder Using NaOH Solution. Nippon Kagaku Kaishi 2000, 10, 725-732. [CrossRef]

42. Janoš, P.; Novak, J.; Broul, M. A Procedure for Obtaining Salts of Rare Earth Elements. U.S. Patent 21039151, 31 October 1988.

43. Terziev, A.L.; Minkova, N.L.; Todorovsky, D.S. Regeneration of waste rare earth oxides based polishing materials. Bulg. Chem. Commun. 1996, 29, 274-284.

44. Um, N.; Hirato, T. A hydrometallurgical method of energy saving type for separation of rare earth elements from rare earth polishing powder wastes with middle fraction of ceria. J. Rare Earths 2016, 34, 536-542. [CrossRef]

45. Um, N.; Hirato, T. Conversion kinetics of cerium oxide into sodium cerium sulfate in $\mathrm{Na}_{2} \mathrm{SO}_{4}-\mathrm{H}_{2} \mathrm{SO}_{4}-\mathrm{H}_{2} \mathrm{O}$ solutions. Mater. Trans. 2012, 53, 1992-1996. [CrossRef]

46. Um, N.; Hirato, T. Synthesis of Sodium Cerium Sulfate (NaCe(SO4)2 ·H2O) from Cerium Oxide in Sulfuric Acid Solutions. In Zero-Carbon Energy Kyoto 2011: Special Edition of Jointed Symposium of Kyoto University Global COE "Energy Science in the Age of Global Warming"; Yao, T., Ed.; Springer: Tokyo, Japan, 2012; pp. 171-176. ISBN 978-4-431-54067-0.

47. Yoon, H.; Kim, C.; Kim, S.; Lee, J.; Cho, S.; Kim, J. Separation of Rare Earth and Aluminium from the Dried Powder of Waste Cerium Polishing Slurry. J. Korean Inst. Resour. Recycl. 2003, 12, 10-15.

48. Um, N.; Hirato, T. Precipitation of cerium sulfate converted from cerium oxide in sulfuric acid solutions and the conversion kinetics. Mater. Trans. 2012, 53, 1986-1991. [CrossRef]

49. Janoš, P.; Novák, J.; Broul, M.; Loučka, T. Regeneration of polishing powders based on REE oxides from glass polishing sludges. Chem. Prum. 1987, 37-62, 189-194.

50. Xie, F.; Zhang, T.A.; Dreisinger, D.; Doyle, F. A critical review on solvent extraction of rare earths from aqueous solutions. Miner. Eng. 2014, 56, 10-28. [CrossRef]

51. Byrne, R.H.; Li, B. Comparative complexation behavior of the rare earths. Geochim. Cosmochim. Acta 1995, 59, 4575-4589. [CrossRef]

52. Kim, E.; Osseo-Asare, K. Aqueous stability of thorium and rare earth metals in monazite hydrometallurgy: Eh-pH diagrams for the systems Th-, $\mathrm{Ce}-, \mathrm{La}-, \mathrm{Nd}-\left(\mathrm{PO}_{4}\right)-\left(\mathrm{SO}_{4}\right)-\mathrm{H}_{2} \mathrm{O}$ at $25^{\circ} \mathrm{C}$. Hydrometallurgy 2012, 113-114, 67-78. [CrossRef]

53. Marsac, R.; Réal, F.; Banik, N.L.; Pédrot, M.; Pourret, O.; Vallet, V. Aqueous chemistry of Ce(iv): Estimations using actinide analogues. Dalt. Trans. 2017, 46, 13553-13561. [CrossRef] [PubMed]

54. Janoš, P.; Kuran, P.; Kormunda, M.; Stengl, V.; Grygar, T.M.; Dosek, M.; Stastny, M.; Ederer, J.; Pilarova, V.; Vrtoch, L. Cerium dioxide as a new reactive sorbent for fast degradation of parathion methyl and some other organophosphates. J. Rare Earths 2014, 32, 360-370. [CrossRef]

(C) 2018 by the authors. Licensee MDPI, Basel, Switzerland. This article is an open access article distributed under the terms and conditions of the Creative Commons Attribution (CC BY) license (http://creativecommons.org/licenses/by/4.0/). 